\title{
Dawn chorus variation in East-Asian tropical montane forest birds and its ecological and morphological correlates
}

\author{
Wei-Ming Chen ${ }^{1}$, Ya-Fu Lee ${ }^{1,5}$, Chi-Feng Tsai ${ }^{1}$ Cheng-Te Yao², Yung-Hsiu Chen ${ }^{3}$ Shou-Hsien Li $^{4}$, Yen-Min Kuo \\ ${ }^{1}$ Department of Life Sciences, National Cheng Kung University, Tainan 701, Taiwan \\ ${ }^{2}$ Taiwan Endemic Species Research Institute, Nantou 552, Taiwan \\ ${ }^{3}$ Liouguei Research Center, Taiwan Forestry Research Institute, Kaohsiung 84442, Taiwan \\ ${ }^{4}$ Department of Life Sciences, National Taiwan Normal University, Taipei 106, Taiwan \\ ${ }^{5}$ E-mail: yafulee@mail.ncku.edu.tw
}

Key words: breeding, canopy, diets, eye size, foraging, perch, Taiwan, tropical forests

\begin{abstract}
Many birds in breeding seasons engage in vigorous dawn singing that often turns to a prominent chorus. We examined dawn chorus variation of avian assemblages in a tropical montane forest in Taiwan and tested the hypothesis that onset sequence is affected by eye sizes, foraging heights, and diet of birds. Chorus onset and duration varied between sampling months, but generally peaked in the prime breeding season. Overall dawn chorus length increased with, but mean duration per species was negatively correlated with, species richness. The inter-correlation among trait variables in phylogenetic independent contrasts was calculated and examined. Both foraging height and relative eye size were selected as positively explanatory factors, but no dietary effects were detected, for chorus onsets. Dawn singing onsets also tended to delay as decreasing log (eye sizes) that, however, was not selected with enough explanatory power. The positive relationship of chorus onsets versus relative eye sizes contradicts our prediction, yet the negative correlation of relative eye sizes with log (eye sizes) indicates an allometric constraint on eye sizes along with increasing body sizes. Lowerlayer species initiated singing earlier than upper-layer species, which complies with the positive correlation of onsets with foraging heights and supports our prediction. This pattern may be condition-specific and more likely occurs in forests lacking a sufficient canopy height and layering and a distinct light difference among forest layers. Foraging heights were additionally found negatively correlated with canopy coverage and slightly positively correlated with ground coverage of perches. Our results concord that foraging height is a relevant factor as eye size in determining the onset and sequence of dawn chorus, yet, suggest that forest settings and vegetation structure may likely complicate the prediction.
\end{abstract}

\section{Contents}

Introduction

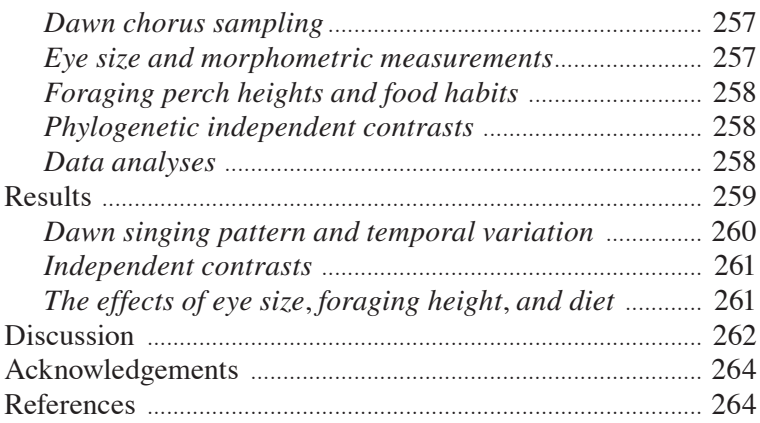

\section{Introduction}

Many bird species, notably but not exclusively the songbirds (Passeriformes), use vocal sounds to fulfill intersexual interactions, such as self-advertising and stimulating mates (e.g., Kroodsma, 1976; Otter and Ratcliffe, 1993; Welling et al., 1995), or intrasexual interactions like social communication and acquiring or defending territory (Amrhein and Erne, 2006; Foote et al., 2008), or both. This behaviour is particularly prominent at dawn and for males in the breeding seasons (Slagsvold, 1996; Kunc et al., 2005; McNeil et al., 2005; Amrhein and Erne, 2006), and often turns into a collective phenomenon known as dawn chorus.

While the association of dawn chorus with the breeding seasons offers ontogenetic (i.e., sexual maturity) and mechanistic (i.e., hormone) explanations, the reasons why male birds engage in vocal activity vigorously at dawn appear to be due to, at least in part, certain proximate physical factors that are not mutually exclusive, and also carry functional perspectives. Lower temperatures and high humidity at dawn may restrict 
activity of both birds and their prey (Avery and Krebs, 1984), but also that of predators that otherwise would be attracted to bird calls. In contrast, lower wind speed and background noise levels in this period are more energetic-efficient and favourable for sound travel with consistency (i.e., the acoustic transmission hypothesis; Henwood and Fabrick, 1979; Cuthill and Macdonald, 1990; Brown and Handford, 2003; but see Dabelsteen and Mathevon, 2002). The limited light level at dawn prohibits diurnal birds from many daytime activities, such as foraging (i.e., the inefficient foraging hypothesis; Kacelnik, 1979; Kacelnik and Krebs, 1982) or social contacts with one another (Cuthill and Macdonald, 1990), but the latter can be achieved vocally (Kacelnik, 1979; Amrhein and Erne, 2006; Foote et al., 2008).

Temporal variation in dawn chorus may also be caused by proximate factors such as light availability that is usually, but not completely (see Kempenaers $e t$ al., 2010; Da Silva et al., 2015), related to time, weather, and vegetation (Berg et al., 2006). Overnight birds may have surplus energy from previous feeding to sustain the night time fast and a lower temperature, which helps to explain why birds can afford to delay foraging and instead engage in singing at dawn (i.e., energy storage stochasticity hypothesis; Hutchinson, 2002). This reasoning concerns more on the variability of participation, so individual variation in quality or status can be assessed (i.e., state-dependent), but does not directly address the sequence and variation at dawn singing among species (Cuthill and Macdonald, 1990; Berg et al., 2006). Masking of signals, such as by noise, carry additional cost and negatively impact avian reproductive success (Halfwerk et al., 2011). Simultaneous songs by various species may also interfere with each other and affect the transmission effectiveness, thus a temporal asynchrony to avoid signal overlapping should be favored (Cody and Brown, 1969; Ficken et al., 1974; Popp et al., 1985).

Species may differ in their sensitivity to light, therefore sense the light level effectively at slightly different time or place (Thomas et al., 2002; McNeil et al., 2005; Berg et al., 2006). This has been noted particularly for species in forested areas (e.g., Popp et al., 1985). In addition, singing attracts predators as well as potential mates, but a bird may lower its alert to potential hazards while singing. Thus, birds should be selected for to sing only if they are able to scan sufficiently the surrounding at a certain light level (Thomas et al., 2002). It is expected that the earlier a bird sings at dawn, the better it is able to detect the surroundings even at dim light (Hutchinson, 2002; Thomas et al., 2002; McNeil et al., 2005), which may be determined by a bird's visual anatomical features, but also associated with the surrounding settings and light levels where a bird is situated.

Birds with larger eyes tend to have earlier dawn singing (Thomas et al., 2002; McNeil et al., 2005). This is supported by anatomical relationships that larger-eyed birds own higher numbers of light-sensitive visual cells on the retina, a thicker inner retinal layer, and more neuron synapses, all these indicating a better visual sensitivity and higher resolution for low light conditions (Hart, 2001a, 2001b; Garamszegi et al., 2002; McNeil et al., 2005). Forest layers, due to the amount of foliage overhead, can have different light levels, and birds perching at a higher place usually receive a richer light availability. Yet, the position chosen by a bird for signaling (i.e., songposts) may not be the same as, and often is higher than, that used for roosting and foraging (Hunter, 1980; Barker and Mennill, 2009). Most forest birds foraging at lower-layers or on the ground also tend to roost at higher places or even up to the canopy at night. In contrast, species adapted to constantly foraging at lower heights or on the ground may have evolved a higher visual sensitivity and acuity that allows them to sense better in dim light earlier (McNeil et al., 2005; Thomas et al., 2006).

Further, avian foraging relies heavily on visual cues, so different visual sensitivities may have evolved in species adapted to different diets (Hart, 2001b; Garamszegi et al., 2002; Fernández-Juricic et al., 2004). Compared to plant resources, prey are often vigilant, requiring rapid detection by birds, or cryptic in coloration or pattern, both require substantial light levels to detect. In case of insect swarms, aerial insectivores are generally equipped with a larger degree of movement sensitivity and resolution-related double cone cells for detecting prey in movement at fast speeds (Hart, 2001a). Thus, predatory birds should have better visual capacity and light sensitivity to effectively sesarch for prey, particularly for foraging within a forest setting (Thomas et al., 2002; McNeil et al., 2005).

We examined the pattern and seasonal variation of avian dawn chorus in a tropical montane forest in Taiwan, where related information is extremely sparse. We tested whether species richness and the assemblage composition affect dawn chorus, and prediced that a greater number of species engaging in dawn chorus prolong the overall chorus duration but shorten individual species singing lengths. We also tested the hypothesis that the sequence of a dawn chorus can be 
determined by eye size, foraging height, and diet of birds, and predicted that earlier dawn singing is associated with species of larger relative eye size. In addition, we predicted that birds primarily foraging at forest floor or lower heights will sing earlier, and predatory birds will have an earlier dawn singing than plant-eating species.

\section{Materials and methods}

\section{Study sites}

Field work took place between March and October, 2007 and 2008, in the Liouguei Experimental Forest (LEF) surrounding the Shanping Field Station $\left(23^{\circ} 55^{\prime} \mathrm{N}, 120^{\circ} 41^{\prime} \mathrm{E}\right.$, ca. 993 ha in area and 550 1200 $\mathrm{m}$ in elevations; Taiwan Forestry Research Institute, TFRI) in Kaohsiung, southern Taiwan. The area is characterized by monthly mean temperature of around $16{ }^{\circ} \mathrm{C}$ in January and $24{ }^{\circ} \mathrm{C}$ in July-August. Rainfall occurs mainly in the monsoon season and often is accompanied by typhoons from May to September, with an accumulated amount of nearly $3000 \mathrm{~mm}$ that accounts for over $85 \%$ of the total annual precipitation (about $3500 \mathrm{~mm}$; Shanping Weather Station data, TFRI).

Secondary forests constitute the vegetation of the study sites, composed of 134 families, 71 species of pteridophytes, 23 species of gymnosperms, 128 species of monocotyledons, and 463 species of dicotyledons (Wang 1991). Dominant vegetation on high hills included mainly Lauraceae [e.g., Beilschmiedia erythrophloia (Hayata), Machilus japonica Siebold \& Zucc., and Cinnamomum camphora (L.) J. Presl.)] and Fagaceae [e.g., Castanopsis carlesii (Hemsl.) Hayata, C. indica (Roxb. ex Lindl.) A. DC., and Cyclobalanopsis glauca Thunb.], whereas Moraceae (e.g., Ficus superba Miq., F. septica Burm.f., F. benjamina L.1767) took over along with Broussonetia papyrifera (L.) Vent., Mallotus paniculatus (Lam.) Mull.Arg., and Trema orientalis (L.) Blume. in riparian valleys.

\section{Dawn chorus sampling}

We monitored dawn chorus at eight replicate sites that were in similar vegetation structure. Any two proximate sites were beyond $250 \mathrm{~m}$ apart in distance, and all sites were away from the main pass or any trails, and thus from potential human disturbance or noise. In each month we conducted two bi-weekly sessions of 4-day dawn sampling, one site each day. The sampling in each session occurred in consecutive four days as possible, and in clear stable weather conditions or nearly so. We randomly alternated the order of site among census days within each month. At each site, we chose a relatively open forest gap that was at least $20 \mathrm{~m}$ in radius to allow for auditory monitoring, and visual observations when light level permitted.

Sampling started $1.5 \mathrm{hr}$ before sunrise at local times (the Central Weather Bureau data, Taiwan), and lasted until dawn singing ended, defined as 20 min after the last singing bout of the last species heard, usually near 08:00. We recorded the onset and end times of each bout of dawn chorus sequences to seconds using a stop watch (Thompson et al., 1994), and the species that made songs, following Severinghaus et al. (2012) and BirdLife International (2014) for the nomenclature. We also tallied song numbers in each bout by a counter. Two consecutive bouts from the same species were distinguished by a silent period, mostly over $10 \mathrm{sec}-$ onds, or occasionally (less than $3.7 \%, n=5510$ ) when two bouts with a pause timed shorter than 10 seconds but were from two identifiable source directions. We acknowledged that our measurements might have been underestimations, but only in a few occasions $(3 \%, n=$ 5510) where singing by two birds of the same species overlapped in time. Prior to our auditory sampling observers were trained and tested for accuracy and consistency by data collected using a super-cardioid condenser microphone (ME66/K6, Sennheiser Electronic, Wedemark, Germany) and a field recorder (Fostex FR-2, Foster Electric Corporation, Tokyo, Japan). The microphone was positioned on a tripod $1.5 \mathrm{~m}$ above the ground and pointed to the most proximate direction of bird sounds, where the sound with maximum intensity was heard. We recorded light level at the onset of each bout of singing using a light meter (1339 Pro, TES Electronic Corporation, Taipei, Taiwan), and humidity and temperature in the beginning and the end of each census by a combined Humidity and Temperature Indicator (WISEWIND, Centenary Materials, Hsinchu, Taiwan).

\section{Eye size and morphometric measurements}

We estimated the eye size of bird species that were recorded in our sites by measuring skull specimens of museum collections (Chen, 2010). We measured orbital morphometric parameters, including the maximum length along the long and short axes of the orbit socket, and the length and width of skull. Eye size in 
volume $\left(E S, \mathrm{~mm}^{3}\right)$ was estimated using $E S=2 \times$ $1.33 \pi a^{2} b$ (Garamszegi et al., 2002), where $a$ and $b$ each represents the long the short axial length of an eye socket. This estimate was strongly correlated $(r=$ $0.97, p<0.05$; Chen, 2010) to that obtained from the approach of applying a series of spherical plastic balls of different sizes to best fit with the eye socket of the birds (Brooke et al., 1999; Thomas et al., 2006). For few species where proper skull specimens were inadequate or completely lacking, we adopted live bird measurements as a substitute. Birds were mist-netted along trails surrounding our study area, and we measured the maximum lengths along the long and short axes of eye socket (to $0.1 \mathrm{~mm}$ ) using an electronic caliper (SV-03 Digital Vernier Caliper, E-BASE, Yunlin, Taiwan). Our netting complied with the legal requirements of Taiwan and the guidelines for the use of animals in research (Sherwin, 2006) throughout our procedures. The orbital measurements $(\mathrm{mm})$ from skull specimens were correlated to direct eye measurements of live birds in both the long axis $(r=0.52, p<0.05)$ and the short axis $(r=0.80, p<0.05$; Chen, 2010), respectively. We corrected our eye measurements using these correlations, but kept the use of this measure to a necessary minimum for a better consistency. We used log-transformed eye size (LES) and its relative value (RES), log (eye size)/log (body mass), for further analyses. The latter considered the allometric effect and was corrected for body size (Berg et al., 2006).

\section{Foraging perch heights and food habits}

For each species engaged in dawn chorus, we located and sighted individuals to record the aspect and the perching locations between 08:00 and 10:00 on the same morning. The distances and heights of perches were visually estimated using on site reference marks, and later corrected by a laser distance meter (Leica DISTO A5). The perch heights were further categorized to up- ( $\geq 7 \mathrm{~m}$ ), mid- ( $\geq 1.5 \mathrm{~m}$ to $<7 \mathrm{~m})$, and bottom $(<1.5 \mathrm{~m})$ layers. We additionally recorded the species and estimated the height of the perch trees, and measured habitat variables surrounding a perch, including canopy and ground coverage.

We determined birds' diets first by onsite observations after dawn chorus during the study period (Chen, 2010), but not every species' foraging was adequately documented due to practical difficulties. We further incorporated data retrieved from Ding et al. (2008), Wu (2008), and those compiled in Severinghaus et al. (2012). We used data that were collected by a similar method in mid-elevation montane areas, prioritizing those with seasons and locations proximate to this study, or adopting their averages when no distinction could be made. We used the item proportions of animal contents at $25 \%$ and $75 \%$ as dividing levels to further classify diets into three classes: animal-eating $(\geq$ $75 \%$ ), omnivores ( $\geq 25$ but $<75 \%$ ), and plant-eating ( $<$ 25\%; Remsen and Parker, 1984). Animal contents here refer only to insects and non-insect invertebrates. We excluded true carnivores, and birds that are active nocturnally or often vocalize in the night, such as night herons, were also excluded.

\section{Phylogenetic independent contrasts}

We grouped species engaging in the dawn chorus into three rooted and unambiguous clades: Galliformes (Phasianidae), Piciformes (Picidae and Ramphastidae), and passerines. To assure independence of observations, we calculated Felsenstein's (1985) phylogenetic independent contrasts in character traits. The contrast calculation was conducted using a phylogenetic hypothesis based on Sibley and Ahlquist (1990), and incorporating recent treatments on the Old World babblers (Timaliidae; Baker et al., 2001; Cibois, 2003; Collar and Robson, 2007), and the results from cytochrome oxidase subunit I (COI) sequence analyses (CT Yao and SH Li, unpubl. data) for interspecific relationships within this group. Phylogenetic independent contrasts were calculated using COMPARE, assuming that the character evolution can be described in a random walk mode, equal branch lengths, and negligible within species variation compared to that among species (Martins, 2004).

\section{Data analyses}

Data are presented as mean \pm standard error (SE) unless otherwise noted. We performed statistical analyses using MINITAB 14.12 (Minitab 2003) and SPSS 12.0.1 (SPSS 2000) for Windows 2000, and set the significance level at $\alpha=0.05$. We corrected onset times relative to the local sunrise to obtain the relative onset times of dawn singing, and calculated duration of dawn signing, for each species and each dawn chorus sequence (Lein, 2007; Liu and Kroodsma, 2007; Foote et al., 2008). We adopted multivariate analysis of variance (MANOVA) with Wilks' $\Lambda$ to examine the temporal (sampling month and year) and spatial (elevation) variation in onset time, total chorus duration, and mean chorus duration. Analysis of variance (ANOVA) 
was used to examine the differences in onset time among birds of different eye-size groups and foraging heights. In both analyses, we conducted post-hoc comparisons using Fisher's least significant difference (LSD) to locate differences. Pearson's correlation analysis was used to examine the relationships of onset time and chorus duration with number of species engaged in dawn singing. The inter-correlation among trait variables, eye size, perching height, and diet content, in independent contrasts was examined using COMPARE (Martins, 2004), and tested by Student's $t=r /\left[\sqrt{ }\left(1-r^{2}\right) / \sqrt{ }(n-2)\right]$, where $r$ is correlation coefficient and $n$ is sample size. We restricted this analysis to species that associated ecological and morphological data were fully available and that occurred in all sampling sites. We further adopted the contrasts to examine the effects of eye size, perching height, and food habit on onset of dawn signing among species using stepwise regression analysis, if each of the correlation coefficients between paired variables was less than
0.8 , setting $\alpha=0.05$ for adding a variable to the model (Zar, 2010).

\section{Results}

We recorded 112 dawn chorus sequences comprising of 5510 bouts of songs or calls (mean: $49.2 \pm 1.94$, range: 4 90), made by 21 species of 15 passerine families, two species of Piciformes, and two species of Galliformes (Table 1). Rusty-cheeked (Pomatorhinus erythrogenys Vigors 1832) and Streak-breasted Scimitar Babblers ( $P$. ruficollis Hodgson 1836), Greycheeked Fulvettas (Alcippe morrisonia Swinhoe 1863), Taiwan Barbets [Psilopogon nuchalis (Gould, 1863)], and Taiwan Whistling Thrushes (Myophonus insularis Gould, 1862) were the most frequent species engaging in dawn chorus. They were followed by Taiwan Patridges [Arborophila crudigularis (Swinhoe, 1864)], White-bellied Yuhinas [Erpornis zantholeuca

Table 1. Relative occurrence $(\%)$, mean $( \pm \mathrm{SE})$ perching height $(\mathrm{m})$, relative eye size (see the text), and diet (percent animal content) of the 25 species of birds studied. Sample sizes of each species for height and eye size are in parentheses after each value.

$\dagger$ B: bottom-layer, M: mid-layer, U: upper-layer; $\ddagger$ S: small (size $\leq 2.4)$, M: medium $(2.4<$ size $\leq 3.4)$, and L: large (size > 3.4); §A: animal-eater, O: omnivores, P: plant-eater.

\begin{tabular}{|c|c|c|c|c|c|}
\hline Species & & Rel. Occur. & Height $\dagger$ & Rel. Eye Size $\neq$ & Diet \\
\hline Campephagidae & Pericrocotus solaris & 4.61 & $15.85 \pm 1.36^{\mathrm{U}}(38)$ & $3.26 \pm 0.05^{\mathrm{L}}(5)$ & $87.5^{\mathrm{A}}$ \\
\hline \multirow[t]{2}{*}{ Corvidae } & Dendrocitta formosae & 3.94 & $9.42 \pm 0.76^{\mathrm{U}}(44)$ & $2.32 \pm 0.03^{\mathrm{S}}(5)$ & $61.3^{\circ}$ \\
\hline & Urocissa caerulea & 1.93 & $8.22 \pm 1.37^{\mathrm{U}}(9)$ & $2.21^{\mathrm{s}}(1)$ & $61.0^{\circ}$ \\
\hline Dicruridae & Dicrurus aeneus & 3.35 & $13.55 \pm 1.86^{\mathrm{U}}(9)$ & $2.93^{\mathrm{M}}(1)$ & $100.0^{\mathrm{A}}$ \\
\hline Leiothrichidae & Yuhina brunneiceps & 1.51 & $10.00^{\mathrm{U}}(1)$ & $3.52 \pm 0.02^{\mathrm{L}}(29)$ & $30.6^{\mathrm{O}}$ \\
\hline Megalaimidae & Psilopogon nuchalis & 7.54 & $11.19 \pm 0.73^{\mathrm{U}}(71)$ & $2.35 \pm 0.03^{\mathrm{s}}(13)$ & $10.0^{\mathrm{P}}$ \\
\hline Monarchidae & Hypothymis azurea & 3.69 & $4.13 \pm 0.35^{\mathrm{M}}(29)$ & $3.56 \pm 0.11^{\mathrm{L}}(3)$ & $95.7^{\mathrm{A}}$ \\
\hline Motacillidae & Motacilla alba & $<0.1$ & -- & $2.81 \pm 0.09^{\mathrm{M}}(3)$ & $100.0^{\mathrm{A}}$ \\
\hline \multirow[t]{3}{*}{ Muscicapidae } & Myiomela leucura & 0.92 & $0.46 \pm 0.26^{\mathrm{B}}(3)$ & $2.94 \pm 0.02^{\mathrm{M}}(20)$ & $100.0^{\mathrm{A}}$ \\
\hline & Niltava vivida & 0.84 & $13.00^{\mathrm{U}}(1)$ & $3.15 \pm 0.14_{M}(4)$ & $100.0^{\mathrm{A}}$ \\
\hline & Rhyacornis fuliginosa & 1.42 & $0.00 \pm 0.00^{\mathrm{B}}(8)$ & $3.42 \pm 0.08^{\mathrm{L}}(5)$ & $100.0^{\mathrm{A}}$ \\
\hline Paridae & Parus monticolus & 0.25 & --- & $3.65 \pm 0.13^{\mathrm{L}}(14)$ & $100.0^{\mathrm{A}}$ \\
\hline \multirow[t]{2}{*}{ Pellorneidae } & Alcippe brunnea & 4.86 & $0.37 \pm 0.10^{\mathrm{B}}(9)$ & $3.26 \pm 0.07^{\mathrm{L}}(5)$ & $100.0^{\mathrm{A}}$ \\
\hline & Alcippe morrisonia & 7.54 & $3.95 \pm 0.20^{\mathrm{M}}(99)$ & $3.45 \pm 0.02^{\mathrm{L}}(58)$ & $59.2^{\circ}$ \\
\hline \multirow{2}{*}{ Phasianidae } & Arborophila crudigularis & 6.2 & $0.25 \pm 0.25^{\mathrm{B}}(2)$ & --- & $>50.0^{\circ}$ \\
\hline & Bambusicola thoracicus & 4.52 & $0.04 \pm 0.04^{\mathrm{B}}(11)$ & $1.79 \pm 0.03^{\mathrm{s}}(3)$ & $93.0^{\mathrm{A}}$ \\
\hline Picidae & Dendrocopos canicapillus & 2.93 & $9.33 \pm 1.53^{\mathrm{U}}(18)$ & $3.05^{\mathrm{M}}(1)$ & $100.0^{\mathrm{A}}$ \\
\hline Pycnonotidae & Hypsipetes leucocephalus & 5.28 & $16.73 \pm 1.37^{\mathrm{U}}(42)$ & $2.47 \pm 0.03^{\mathrm{M}}(5)$ & $20.4^{\mathrm{P}}$ \\
\hline Sylviidae & Abroscopus albogularis & 2.01 & $4.20 \pm 1.20^{\mathrm{M}}(5)$ & $5.05 \pm 0.09^{\mathrm{L}}(13)$ & $100.0^{\mathrm{A}}$ \\
\hline \multirow[t]{4}{*}{ Timaliidae } & Heterophasia auricularis & 1.59 & $7.38 \pm 1.18^{\mathrm{U}}(9)$ & $2.48 \pm 0.03^{\mathrm{M}}(22)$ & $55.9^{\circ}$ \\
\hline & Pomatorhinus erythrogenys & 7.79 & $0.67 \pm 0.09^{\mathrm{B}}(16)$ & $2.32 \pm 0.13^{s}(3)$ & $100.0^{\mathrm{A}}$ \\
\hline & Pomatorhinus ruficollis & 7.71 & $1.42 \pm 0.20^{\mathrm{B}}(52)$ & $2.67 \pm 0.04^{\mathrm{M}}(11)$ & $60.6^{\mathrm{O}}$ \\
\hline & Stachyridopsis ruficeps & 5.95 & $1.14 \pm 0.20^{\mathrm{B}}(11)$ & $3.58 \pm 0.05^{\mathrm{L}}(24)$ & $72.9^{\circ}$ \\
\hline Turdidae & Myiophoneus insularis & 7.54 & $0.77 \pm 0.22^{\mathrm{B}}(23)$ & $2.26 \pm 0.08^{\mathrm{S}}(4)$ & $100.0^{\mathrm{A}}$ \\
\hline Vireonidae & Erpornis zantholeuca & 6.03 & $5.07 \pm 0.30^{\mathrm{M}}(49)$ & $3.80 \pm 0.09^{\mathrm{L}}(7)$ & $95.5^{\mathrm{A}}$ \\
\hline
\end{tabular}


(Blyth, 1844)], Rufous-capped Babblers (Stachyridopsis ruficeps Blyth, 1847), and Black Bulbuls (Hypsipetes leucocephalus Müller, 1776). Each of these species accounted for greater than 5\% and collectively nearly $62 \%$ of the total occurrence in dawn chorus (Table 1).

\section{Dawn singing pattern and temporal variation}

A dawn chorus sequence began from 74.0 to $11.6 \mathrm{~min}$ before sunrise (mean $30.86 \pm 0.81 \mathrm{~min}$ ), and lasted from 33.65 to $233.03 \min (115.29 \pm 4.10 \mathrm{~min} ; n=112)$. Both the relative onset times and the chorus duration were affected by the sampling year (MANOVA: Wilks' $\left.\Lambda=0.833, F_{(3,68)}=4.532, p=0.006\right)$ and month (Wilks' $\Lambda=0.542, F_{(15,188)}=3.113, p<0.001$ ) with in-

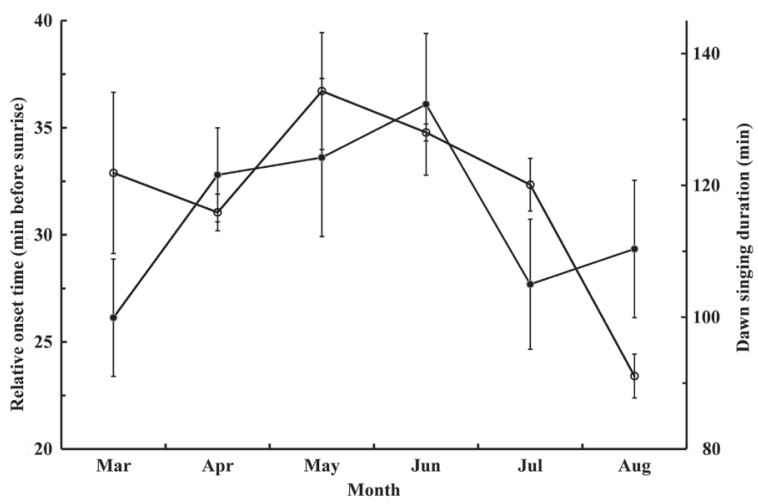

Fig. 1. Mean ( \pm SE) relative onset times (min; - O-) of first song and chorus duration (min; - -) at dawn by birds in the LEF sites over months (onset times: Aug < Mar, Apr, May, June, and Jul, all $p$ values $<0.005$; singing lengths: Jun $>$ Mar, Jun $>$ Jul, $p$ values $<0.05$ ).

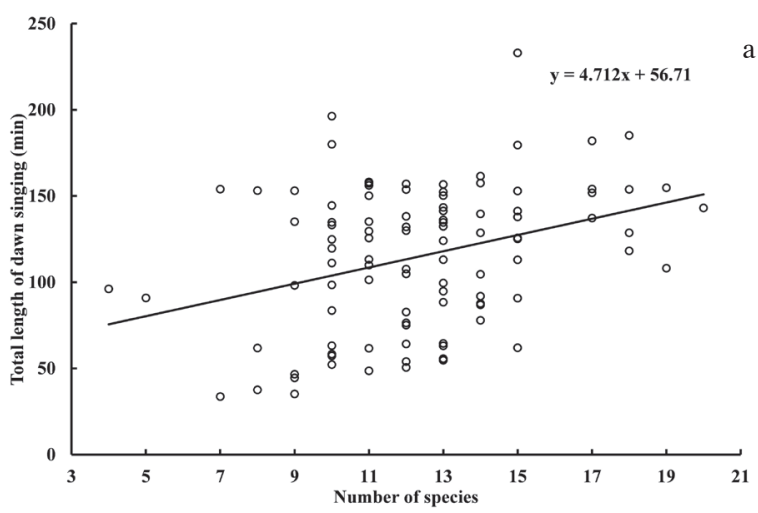

teraction (Wilks' $\Lambda=0.537, F_{(15,188)}=3.165, p<0.001$ ), but not by the elevation range of sites (Wilks' $\Lambda=$ $\left.0.918, F_{(3.68)}=2.037, p=0.117\right)$. Relative onset times advanced the most in May (Fisher's LSD, May > April, $p<0.05)$ and then progressively delayed toward August (all $p$ values $<0.005$ or 0.001 ). In contrast, mean dawn chorus last longer in early summer and peaked in June (Fisher's LSD, June $>$ March, $p<0.05$; June $>$ July, $p<0.05$; Fig. 1). The dawn chorus duration was positively $\left(r=0.34, F_{(1,92)}=8.697, p<0.005\right.$; Fig. 2a), but the mean singing duration per species negatively $(r$ $=0.28, F_{(1,92)}=7.513, p<0.01$; Fig. 2 b), correlated to the number of bird species engaging in a chorus, whereas relative onset times showed no correlation $(r=0.118$, $\left.F_{(1,92)}=0.02, p=0.887\right)$.

Among species, $M$. insularis initiated the earliest singing and had the longest duration. It was followed by A. morrisonia and $P$. erythrogenys, and then by $A$. crudigularis and $P$. ruficollis in onset time, with their mean onsets earlier than or close to the sunrise, while all other species started singing 5 min or longer after the sunrise. In contrast, singing duration of A.crudigularis and P. ruficollis was among the shortest (Fig. 3). When only the singing of each species engaging as the first starter in a chorus was considered, the duration and relative onsets of dawn singing also fluctuated among species (MANOVA: Wilks' $\Lambda=0.73, F_{(8,192)}=$ $4.067, p<0.001)$. First song of A. morrisonia (44.16 \pm 15.16 min before sunrise) exceeded $M$. insularis (30.51 \pm 0.65 min before sunrise; Fisher's LSD, $p<0.05)$ in onset time, and was earlier than A. crudigularis (27.07 \pm 0.55 min before sunrise; Fisher's LSD, $p<0.05$ ), but not significantly different from $P$. erythrogenys (35.03 \pm 17.91 min before sunrise) and P. ruficollis (30.29 \pm $8.07 \mathrm{~min}$ before sunrise). The singing duration of $A$.

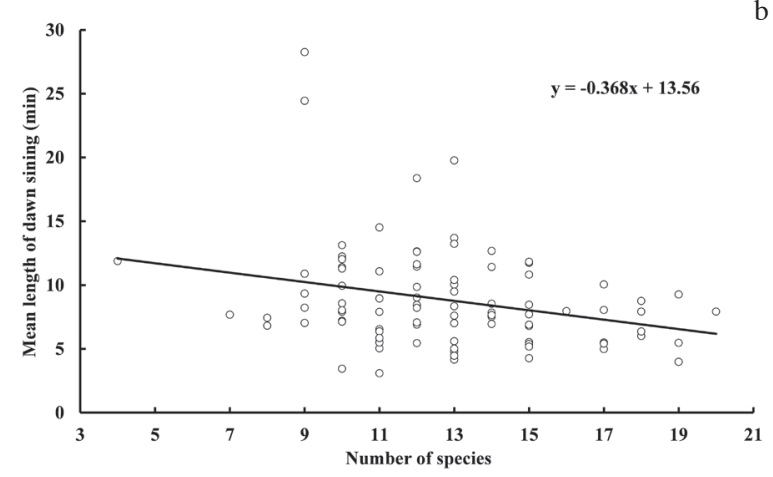

Fig. 2. The correlation of (a) total chorus length and (b) mean singing length per species to number of species engaged in dawn chorus in the Liouguei Experimental Forest. 
morrisonia (47.51 \pm 11.08 min; Fisher's LSD, $p<$ $0.001)$ and $P$. ruficollis $(31.8 \pm 8.92 \mathrm{~min})$ also outlast that of M. insularis (17.56 $\pm 1.11 \mathrm{~min}$; Fisher's LSD, $p$ $<0.05)$ and A. crudigularis $(2.81 \pm 2.6 \mathrm{~min}$; Fisher's $\mathrm{LSD}, p<0.005)$.

\section{Independent contrasts}

Phylogenetic independent contrasts in onset time of dawn singing were not correlated to contrasts of height

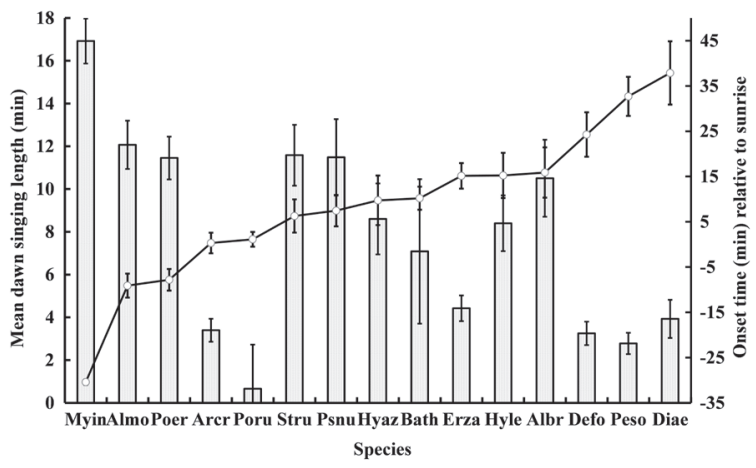

Fig. 3. Mean ( \pm SE) dawn singing duration (min; $\square$ ) and relative onset time (min; - $\bigcirc-$ ) of 15 species of birds that occurred in both years and with the highest occurrence frequency. Species name abbreviation (sample size) are: Albr, Alcippe brunnea (60); Almo, Alcippe morrisonia (106); Arcr, Arborophila crudigularis (86); Bath, Bambusicola thoracicus (60); Defo, Dendrocitta formosae (62); Diae, Dicrurus aeneus (44); Erza, Erpornis zantholeuca (82); Hyle, Hypsipetes leucocephalus (66); Hyaz, Hypothymis azurea (48); Psnu, Psilopogon nuchalis (101); Myin, Myiophoneus insularis (105); Peso, Pericrocotus solaris (64); Poer, Pomatorhinus erythrogenys (109); Poru, Pomatorhinus ruficollis (106); Stru, Stachyridopsis ruficeps (78).

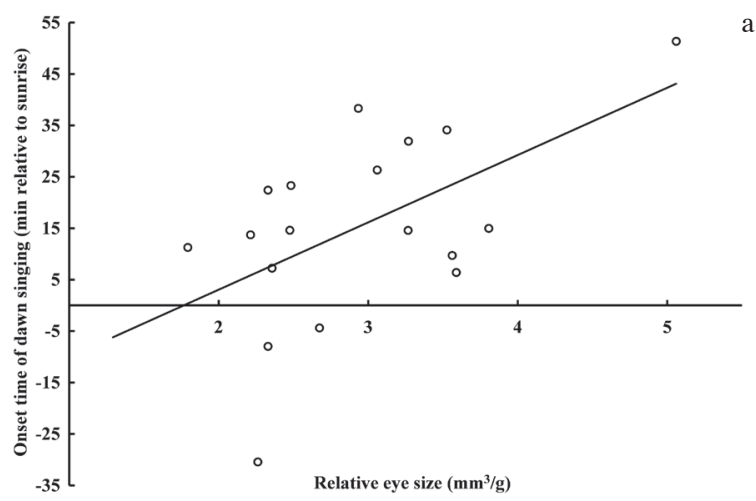

$(r=0.43, t=2.02, p=0.06)$, diet $(r=0.15, t=0.64, p=$ $0.53)$, or log (eye size) $(r=-0.01, t=-0.04, p=0.97)$, and barely with relative eye size $(r=0.45, t=2.14, p=$ 0.05 ; all $d . f .=18$ ). While foraging height contrasts were slightly negatively correlated with diet contrasts $(r=-0.51, t=-2.52, p<0.05)$, the contrasts of log (eye size) (LES) and relative eye size (RES) was neither correlated with that of foraging heights (LES: $r=0.06$, $t=0.26, p=0.80$; RES: $r=-0.10, t=-0.43, p=0.68$ ) nor with diet contrasts (LES: $r=0.20, t=0.87, p=$ 0.40 ; RES: $r=0.44, t=2.08, p=0.06$ ). Thus, foraging height and percent animal content in diet were adopted with the log (eye size) (model I) and the relative eye size (model II), respectively, in further stepwise multiple regression analysis.

\section{The effects of eye size, foraging height, and diet}

In model $\mathrm{I}$, foraging height was firstly chosen $\left(R^{2}=\right.$ $\left.0.28, F_{(1,17)}=6.53, \beta=0.53, t=2.56, p<0.05\right)$, the $\log$ (eye size) barely selected $(\beta=-0.38, t=-1.96, p=0.07)$, and the percent animal content in diet not chosen $(\beta=$ $0.33, t=1.48, p=0.16$ ). Model II, however, picked both foraging height $(\beta=0.53, t=3.21, p=0.005)$ and relative eye size $\left(\beta=0.5, t=2.93, p=0.01 ; R^{2}=0.53, F_{(2}\right.$, $\left.{ }_{16}=9.01, p<0.01\right)$, with the former first chosen and $28 \%$ of variation in dawn singing explained, and adding relative eye size increased the power of explanation by 0.25 .

Among species, mean dawn singing onset time delayed with increasing relative eye size $(r=0.48, p<$ 0.05 ; Fig. $4 a)$, which resulted from a negative correlation between log (eye size) and relative eye size $(r=$ $-0.81, p<0.05)$. Onset time also delayed as increasing foraging height $(r=0.54, p<0.05$; Fig. $4 \mathrm{~b})$, and this

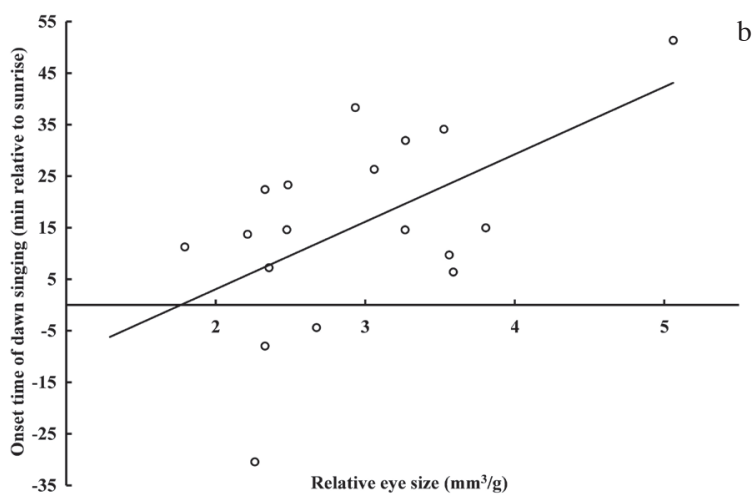

Fig. 4. The correlation between dawn singing onsets of birds and (a) relative eye sizes and (b) foraging heights in the Liouguei Experimental Forest. 
held when data were restricted to passerines $(r=0.57$, $p<0.05)$. Birds customarily associated with different forest layers initiated singing at different times (ANOVA: $\left.F_{(2,16)}=4.51, p<0.05\right)$, with bottom-layer species starting earlier $(-1.74 \pm 6.76 \mathrm{~min}, n=6)$ than those of up-layer $(23.56 \pm 3.43 \mathrm{~min}, n=9$; Fisher's LSD, $p<$ $0.05)$, but neither group differed from birds in the midlayer $(16.72 \pm 12.65 \mathrm{~min}, n=4)$. Eye size also varied among birds associated with different forest layers (MANOVA: Wilks' $\Lambda=0.49, F_{(4,30)}=3.219, p<0.05$ ) but in different ways; while log (eye size) was smaller in mid-layer $(3.72 \pm 0.05$; Fisher's LSD, $p<0.05)$ than in up- $(4.15 \pm 0.12)$ and bottom-layer birds $(4.11 \pm$ 0.14 ), relative eye size was larger in mid-layer (3.96 \pm $0.36)$ than up- $(2.73 \pm 0.16)$ and bottom-layer birds $(2.68 \pm 0.24$; Fisher's LSD, $p<0.005)$. Foraging height, however, was found relating to vegetation variables $\left(R^{2}\right.$ $\left.=0.75, F_{(4,15)}=11.01, p<0.001\right)$, specifically negatively with canopy cover $(t=-6.48, p<0.001)$ and positively with ground cover $(t=2.92, p<0.05)$, but not strongly with the canopy depth $(t=-0.48, p=0.64)$ or a tree's distance to the forest edge $(t=-0.11, p=0.91)$.

\section{Discussion}

Onset and duration of avian dawn chorus in the LEF forest peaked in the prime breeding season of most common birds in this region (Severinghaus et al., 2012). This is consistent with the conclusion that song activity at dawn is mainly associated with female fertility cycles (Mace, 1987). Those birds that sang earlier were mostly insectivores (e.g., M. insularis, P. erythrogenys, and $A$. crudigularis) or omnivores (e.g., $P$. ruficollis and $S$. ruficeps) active on the forest floor. Upper-layer and plant eating H. leucocephalus and $M$. nuchalis appeared in the middle, while most other uplayer dwellers like Grey Tree-pies (Dendrocitta formosae Swinhoe, 1863), Bronzed Drongoes (Dicrurus aeneus Vieillot, 1817), and Grey-chinned Minivets (Pericrocotus solaris Blyth 1846) started relatively late, in a chorus. Mid-layer species that retain a greater chance to explore both upward and downward are presumably equipped with a greater visual or behavioral flexibility, not surprisingly showed a greater variation in their onsets within a chorus sequence. This included the secondly ranked A. morrisonia and species in the middle of a chorus, like Black-naped Monarches [Hypothymis azurea (Boddaert, 1783)] and E. zantholeu$c a$, while other mid-layer dwellers started late in dawn chorus. Interestingly, A. morrisonia, P. erythrogenys and $P$. ruficollis significantly advanced their onsets when engaging as the first birds singing in a dawn chorus, but their overall mean onset times usually were a little later than those of typical first starters. This, together with the confirmed prediction that increasing numbers of species engaged in dawn singing prolonged the chorus duration but decreased the singing duration of each species, suggest that subtle species interactions, such as interspecific hierarchy or competing for singing posts, may be involved in dawn chorus and warrant further detailed investigations.

Our observations and regression results indicate that foraging heights and relative eye sizes, but not log (eye size) and diets, are the more relevant factors affecting the onsets and sequence of avian dawn chorus. This is largely consistent with the notion of a similar influence of ecological factors compared to morphological factors on dawn singing, and supports the speculation that the eye morphology may be more conservative in evolution (Berg et al., 2006). Although with a relatively smaller data set, our results also reveal that species active at lower heights start to sing earlier at dawn, and supports our prediction. This, however, contradicts to that of Berg et al. (2006) showing the opposite and the discrepancy demands explanations.

Heights of birds that make the first songs at dawn are often difficult, if not completely impossible, to observe and measure because of light limitation. Thus foraging heights were adopted as a proxy to infer the environment conditions where birds' singing may be associated with (Berg et al., 2006; this study), but for different reasoning. Birds perching at higher places may receive a greater amount of light and earlier. Yet, birds primarily foraging at certain heights may not roost overnight at the same level. Most birds, including ground foragers like sparrows, pigeons, and herons, roost at higher places at night presumably for the sake of reducing predation risk from the ground. Low-layer or ground foragers could also move upper at dawn to perch and then sing at a light-exposed and more energetic-efficient location. For instance, we observed understory foragers $P$. erythrogenys singing on the top of standing dead tree trunks at places with sparser vegetation, and M. insularis singing up to $4 \mathrm{~m}$ height, both higher than their typical foraging heights (Chen, 2010). The genus name of Taiwan Partirdges (Arborophila), although a typical forest floor forager (Severinghaus et al., 2012), also implies a high-perch association. We reasoned and interpreted foraging heights as the height level where primarily associated species with suffi- 
cient light sensitivity capable of sensing available dim light at dawn before foraging, instead of the height level with its actual light availability at sighting. This concurs with the inefficient foraging hypothesis (Kacelnik and Krebs, 1982).

Under this reasoning, low-layer or ground foragers with sharper sensitivity could sense dim light and initiate singing earlier than upper layer species when roosting at a higher, similar, or even slightly lower level. Only when birds associated with different forest heights partition the layers drastically that upper-layer foragers roost at much higher perches, the light difference between the up and lower levels may outweigh that in light sensitivity between species of different heights. Tree canopies of Neotropical rain forests in previous dawn chorus studies often reach $25 \mathrm{~m}$ or more, easily creating dramatic light gradients between the canopy layer and the forest floor as much as twofold of difference (e.g., Brown and Handford, 2003; Berg et al., 2006). This likely would increase the chance of upper-layer foragers with higher night perches singing at dawn earlier.

In contrast, our study sites comprised of secondary forests where canopy reached 10 12 m only, with less distinctive inter-layer vegetation structure. The difference in light level between the understory and canopy layers was less dramatic, and may reduce the time difference in receiving sufficient light levels to trigger dawn singing. A few meters of shift in this forest setting by species foraging at lower levels would make the actual temporal difference in light availability insignificant, but the species difference in light sensitivity may still do. This thus far is supported by our observations in Fengongshan, an area about $1800 \mathrm{~m}$ in elevation and $5 \mathrm{~km}$ from our sites, where comprised of primary forests of tree heights above $20 \mathrm{~m}$. Top canopy dwellers like Steere's Liocichla Liocichla steerii Swinhoe 1877 and White-eared Sibia Heterophasia auricularis (Swinhoe, 1864) appeared to sing earlier. Those associated with mid-to-upper layer followed, such as Rufous-faced Warbler Abroscopus albogularis, P. nuchalis, and Taiwan Yuhina Yuhina brunneiceps, and were further followed by mid and bottom layer species, including A. morrisonia, $P$. erythrogenys, $P$. ruficollis, A. crudigularis, and $S$. ruficeps, with less differences (YF Lee, unpubl. data).

A greater eye size should contain more visual cells, and potentially is more capable of detecting light in a dim environment (McNeil et al., 2005). Yet, our data showed a positive correlation of relative eye sizes to dawn singing onsets, which contradicts our prediction.
Species in our study comprised of a larger number of single-species families, except timaliids and muscicapids comprising of multiple species. Those of Thomas et al. (2002) were mainly of sylviids and muscicapids, whereas species in Berg et al. (2006) were mostly distinctive to the neo-tropics. Variability among different species lineages might have complicated this discrepancy and requires further investigations. Nonetheless, relative eye sizes were tightly negatively correlated to log eye sizes, resulting in a smaller relative eye size as eye size growing along with body size, an indication of allometric growth of eyes versus body sizes in birds. This is consistent with the finding across 104 bird family (Brooke et al., 1999). In contrast, although the log eye size was only barely selected by the model, but appeared negatively correlated to the dawn singing onset, which still concurs with our prediction.

The light sensitivity of birds may also be affected by anatomical features of eyes other than size. Bergamin et al. (1998) confirmed that in humans brown iris is associated with greater pupillary contraction amplitude, time, contraction velocity, and re-dilation than paler, such as blue, iris. The relationship of iris with light and visual sensitivity in birds is not yet well established. Avian species that are typically adapted to nocturnal activity, and thus are presumably with higher light sensitivity (i.e., Strigidae), have either reddish brown iris, such as Collared Scops Owls (Otus bakkamoena Pennant, 1769), or pale yellowish iris, such as Mountain Scops Owls [O. spilocephalus (Blyth 1846)] and Collared Owlets [Glaucidium brodiei (Burton, 1836)]. Those earliest species engaging in dawn chorus in our study also have either reddish (e.g., M. insularis and A. morrisonia) or pale yellowish iris (e.g., P. erythrogenys and $P$. ruficollis). In addition, the tapetum lucidum, a reflective layer in retina, may increase the amount of light received by photosensitive cells and allow a better vision in low light conditions, and requires further detailed studies.

In comparison, diets of birds did not play any significant effects as predicted. Most of the species recorded $(60 \%)$ were insectivores that presented the entire range in foraging heights, from the forest floor, such as M. insularis, P. erythrogenys, Chinese Bamboo Partridges [Bambusicola thoracicus (Temminck, 1815)], to the medium, such as A. albogularis, E. zantholeuca, and $H$. azurea, to the upper layers, such as $D$. aeneus, P. solaris, and Gray-capped Pygmy Woodpeckers [Dendrocopos canicapillus (Blyth, 1845)]. The variability in perching height may dilute the relationship between diets and onset times of dawn singing. On 
the other hand, it indicates that insectivores can and would locate prey from different heights or forest layers that are exposed to different levels of light availability, thus diets are less liable to be subjected to light constraints (Thomas et al., 2006).

Our results indicate that foraging/perching heights by birds are a considerably more relevant factor in explaining the pattern and difference in dawn signing sequence among species. This ecological factor apparently determines the timing and level of light availability, but is also affected by the visual capability of birds and its effect on dawn chorus of different species can be subjected to the habitat structure. In forests with tall trees and structured vegetation, perching height may overshadow the difference in visual ability, while in forests with less-structured vegetation, lower or thinner canopy, or both, minor differences in visual ability may likely still play a crucial role.

\section{Acknowledgments}

We thank Taiwan Endemic Species Research Institute, National Museum of Natural Science, Academia Sinica Biodiversity Research Museum, and National Taiwan Museum for loaning specimens, the Liouguei Research Center for logistic assistance and a grant support to YH Chen (97Agroscience-11.2.3Forestry-G4; the Council of Agriculture, Taiwan), and YS Young, CF Chiou, CM Lai, CL Hsieh, MH Lai, and HC Liao for assistances in the field. YF Lee was additionally supported (95-2621-B-006-005-MY2) by National Science Council, Taiwan. This manuscript benefited tremendously from three anonymous reviewers' critical and valuable comments. Among authors, WM Chen and YF Lee contributed equally; and CF Tsai, CT Yao, YH Chen, SH Li, and YM Kuo shared an equal contribution.

\section{References}

Amrhein V, Erne N. 2006. Dawn singing reflects past territorial challenges in the Winter Wren. Animal Behaviour 71: 10751080 .

Avery MI, Krebs JR. 1984. Temperature and foraging success of Great Tits (Parus major) hunting for spiders. Ibis 126: 33-38.

Barker FK, Barrowclough GF, Groth JG. 2001. A phylogenetic hypothesis for passerine birds: taxonomic and biogeographic implications of an analysis of nuclear DNA sequence data. Proceedings of the Royal Society London B 269: 295-308.

Barker NKS, Mennill DJ. 2009. Song perch height in Rufousand-White Wrens: does behavior enhance effective communication in a tropical forest? Ethology 115: 897-904.

Berg KS, Brumfield RT, Apanius V. 2006. Phylogenetic and ecological determinants of the neotropical dawn chorus. Proceedings of the Royal Society London B 273: 999-1005.
Bergamin O, Schoetzau A, Sugimoto K, Zulauf M. 1998. The influence of iris color on the pupillary light reflex. Graefe's Archive for Clinical and Experimental Ophthalmology 236: 567-570.

BirdLife International 2014. The BirdLife checklist of the birds of the world: v7. http://www.birdlife.org/datazone/userfiles/ file/Species/Taxonomy/BirdLife_Checklist_Version_70.zip.

Brooke M de L, Hanley S, Laughlin SB. 1999. The scaling of eye size with body mass in birds. Proceedings of the Royal Society London B 266: 405-412.

Brown TJ, Handford P. 2003. Why birds sing at dawn: the role of consistent song transmission. Ibis 145: 120-129.

Catchpole CK, Slater PJB. 2003. Bird song: biological themes and variations. Cambridge: Cambridge University Press.

Chen WM. 2010. The dawn singing sequence and seasonal singing patterns of forest avian assemblages. MS Thesis. Tainan, Taiwan: National Cheng Kung University.

Cibois A. 2003. Mitochondrial DNA phylogeny of babblers (Timaliidae). Auk 120: 35-54.

Cody ML, Brown JH. 1969. Song asynchrony in neighbouring bird species. Nature 222: 778-780.

Collar NJ, Robson C. 2007. Family Timaliidae. Pp 70-291 in: del Hoyo J, Elliott A, Christie DA, eds, Handbook of the Birds of the World v12 Picathartes to Tits and Chickadees. Barcelona, Lynx Edicions.

Cuthill IC, Macdonald WA. 1990. Experimental manipulation of the dawn and dusk chorus in the Blackbird Turdus merula. Behavioral Ecology and Sociobiology 26: 209-216.

Da Silva A, Valcu M, Kempenaers B. 2015. Light pollution alters the phenology of dawnand dusk singing in common European songbirds. Philosophical Transactions of the Royal Society B 370: DOI: 10.1098/rstb.2014.0126.

Dabelsteen T, Mathevon N. 2002. Why do songbirds sing intensively at dawn? Acta Ethologica 4: 65-72.

Ding TS, Liao HC, Yuan HW. 2008. Breeding bird community composition in different successional vegetation in the montane coniferous forests zone of Taiwan. Forest Ecology and Management 255: 2038-2048.

Felsenstein J. 1985. Phylogenies and the Comparative Method. American Naturalist 125: 1-15.

Fernández-Juricic E, Erichsen JT, Kacelnik A. 2004. Visual perception and social foraging in birds. Trends in Ecology and Evolution 19: 25-31.

Ficken RW, Ficken MS, Hailman JP. 1974. Temporal pattern shifts to avoid acoustic interference in singing birds. Science 183: 762-763.

Foote JR, Fitzsimmons LP, Mennill DJ, Ratcliffe LM. 2008. Male chickadees match neighbors interactively at dawn: support for the social dynamics hypothesis. Behavioral Ecology 19: 1192-1199.

Garamszegi LZ, Møller AP, Erritzøe J. 2002. Coevolving avian eye size and brain size in relation to prey capture and nocturnality. Proceedings of the Royal Society London B 269: 961-967.

Halfwerk W, Hollwman LJM, Lessells CM, Slabbekoorn H. 2011. Negative impact of traffic noise on avian reproductive success. Journal of Applied Ecology 48: 210-219.

Hart NS. 2001a. Variations in cone photoreceptor abundance and the visual ecology of birds. Journal of Comparative Physiology A 187: 685-697. 
Hart NS. 2001b. The visual ecology of avian photoreceptors. Progress in Retinal and Eye Research 20: 675-703.

Henwood K, Fabrick A. 1979. A quantitative analysis of the dawn chorus: temporal selection for communicatory optimization. American Naturalist 114: 260-274.

Hunter MLJ. 1980. Micro habitat selection for singing and other behavior in Great Tits, Parus major: some visual and acoustical considerations. Animal Behaviour 28: 468-475.

Hutchinson JMC. 2002. Two explanations of the dawn chorus compared: how monotonically changing light levels favour a short break from singing. Animal Behaviour 64: 527-539.

Kacelnik A. 1979. The foraging efficiency of great tits (Parus major L.) in relation to light intensity. Animal Behaviour 27: 237-241.

Kacelnik A, Krebs JR. 1982. The dawn chorus in the Great Tit (Parus major): proximate and ultimate causes. Behaviour 83: 287-309.

Kempenaers B, Borgström P, Loës P, Schlicht E, Valcu M. 2010. Artificial night lighting affects dawn song, extra-pair siring success, and lay date in songbirds. Current Biology 20: $1735-1739$.

Kroodsma DE. 1976. Reproductive development in a female songbird: differential stimulation by quality of male song. Science 192: 574-575.

Kunc HP, Amrhein V, Naguib M. 2005. Seasonal variation in dawn song characteristics in the common nightingale. Animal Behaviour 70: 1265-1271.

Lein MR. 2007. Patterns of dawn singing by Buff-breasted Flycatchers. Journal of Field Ornithology 78: 343-351.

Liu WC, Kroodsma DE. 2007. Dawn and daytime singing behavior of Chipping Sparrows (Spizella passerina). Auk 124: 44-52.

Mace R. 1987. The dawn chorus in the great tit Parus major is directly related to female fertility. Nature 330: 745-746.

Martins EP. 2004. COMPARE, v. 4.6b. Computer programs for the statistical analysis of comparative data. Distributed by the author at http://compare.bio.indiana.edu/. Bloomington, Indiana, USA: Indiana University.

Martins EP, Hansen TF. 1997. Phylogenies and the comparative method: a general approach to incorporating phylogenetic information into the analysis of interspecific data. American Naturalist 149: 646-667.

McNeil R, McSween A, Lachapelle P. 2005. Comparison of the retinal structure and function in four bird species as a function of the time they start singing in the morning. Brain, Behavior and Evolution 65: 202-214.

Minitab Inc. 2003. MINITAB ${ }^{\circledR}$ 14.12. Statistical Software. Pennsylvania: Minitab Inc.

Otter K, Ratcliffe L. 1993. Changes in singing behavior of male black-capped chickadees (Parus atricapillus) following mate removal. Behavioral Ecology and Sociobiology 33: 409-414.

Popp JW, Ficken RW, Reinartz JA. 1985. Short-term temporal avoidance of interspecific acoustic interference among forest birds. Auk 102: 744-748.

Remsen JV, Parker TA. 1984. Arboreal dead-leaf-searching birds of the neotropics. Condor 86: 36-41.

Severinghaus LL, Ding TS, Fang WH, Lin WH, Tsai MC, Yen CW. 2012. The Avifauna of Taiwan. Taipei: Forestry Bureau, COA, Taiwan.

Sherwin CM. 2006. Guidelines for the treatment of animals in behavioural research and teaching. Animal Behaviour 71: 245-253.

Sibley CG, Ahlquist JE. 1990. Phylogeny and Classification of Birds. New Haven: Yale University Press.

Slagsvold T. 1977. Bird song activity in relation to breeding cycle, spring weather, and Environmental phenology. Ornis Scandinavica 8: 197-222.

Slagsvold T. 1996. Dawn and dusk singing of male American Robins in relation to female behavior. Wilson Bulletins 108: 507-515.

SPSS Inc. 2000. SPSS 12.0. Chicago: SPSS Inc.

Sutherland WJ. 2006. Ecological Census Techniques: a Handbook. Cambridge: CambridgeUniversity Press.

Thomas RJ, Széskely T, Cuthill IC, Harper DGC, Newson SE, et al. 2002. Eye size in birds and the timing of song at dawn. Proceedings of the Royal Society London B 269: 831-837.

Thomas RJ, Széskely T, Powell RF, Cuthill IC. 2006. Eye size, foraging methods and the timing of foraging in shorebirds. Functional Ecology 20: 157-165.

Thompson, N.S., LeDoux, K., Moody, K. 1994. A system for describing bird song units. Bioacoustics 5: 267-279.

Wang SH. 1991. Ordination and classification of vegetation in Sanping and Nanfen Shan areas. Taiwan Journal of Forestry Science 6: 185-201.

Welling P, Koivula K, Lahti K. 1995. The dawn chorus is linked with female fertility in the Willow Tit Parus montanus. Journal of Avian Biology 26: 241-246.

Wu JC. 2008. Forest avifauna, diet, and altitudinal migration in Peitawushan. MS Thesis. Taiwan: National Pingtung University of Science and Technology.

Zar JH. 2010. Biostatistical Analysis. Fifth edition. London: Peasron Education.

Received: 31 October 2014

Revised and accepted: 13 May 2015

Published online: 6 October 2015

Editor: V. Nijman 